\title{
Direct Process to Prepare Crystallized Freestanding Membranes of Hydroxyapatite Using Sacrificial Layer of Barium-Compounds
}

\author{
Hiroaki Nishikawa*, Takafumi Nishii \\ Faculty of Biology-Oriented Science and Technology, Kindai University, Kinokawa, Japan \\ Email: *nishik32@waka.kindai.ac.jp
}

How to cite this paper: Nishikawa, H. and Nishii, T. (2017) Direct Process to Prepare Crystallized Freestanding Membranes of Hydroxyapatite Using Sacrificial Layer of Barium-Compounds. Journal of Crystallization Process and Technology, 7, 48-53. https://doi.org/10.4236/jcpt.2017.72003

Received: February 27, 2017

Accepted: April 27, 2017

Published: April 30, 2017

Copyright ( 92017 by authors and Scientific Research Publishing Inc. This work is licensed under the Creative Commons Attribution International License (CC BY 4.0).

http://creativecommons.org/licenses/by/4.0/

\begin{abstract}
Freestanding membrane (FSM) of hydroxyapatite (HA) is a thin sheet of pure HA without any supporting substrates. Our original preparation process of FSM of HA had three steps: The first was the deposition of HA layer on sacrificial layer of solvent-soluble materials, the second was separation of FSM of HA by means of dissolution of sacrificial layer, and the third was postannealing to crystallize FSM of HA. To date, the post-annealing process was a serious bottleneck of productivity owing to its too long time. In this short report, we proposed a novel sacrificial layer, heatproof and water-soluble Bacompound, which makes the direct deposition of crystallized HA possible due to its heatproof property because the problem on the original process was that the previous sacrificial layers have no heatproof property and HA layer should be deposited as amorphous. We can deposit the Ba-compound sacrificial layer only in 1 hour followed with the direct deposition of crystallized HA layer, substituting the 20 hours of post-annealing. The FSM of HA was separated successfully from the substrate by means of dissolution of Ba-compound with water. Our novel process can shrink the process time by 19 hours.
\end{abstract}

\section{Keywords}

Freestanding Membrane, Hydroxyapatite, Sacrificial Layer, Ba-compounds

\section{Introduction}

Hydroxyapatite (HA), $\mathrm{Ca}_{10}\left(\mathrm{PO}_{4}\right)_{6}(\mathrm{OH})_{2}$, is a main inorganic component of bones and teeth, and widely used as a biomaterial due to its excellent biocompatibility and osteoconductivity. One of promising applications of HA is a scaffold for cell cultivation [1]. To date, we have investigated preparation techniques and its applications of a "freestanding membrane (FSM)" of HA [2]-[9]. As the name sug- 
gests, the FSM of HA is a thin sheet of HA (typically $\mu$ m-order thick) without any supporting substrates. Because the FSM of HA consists of pure HA alone, we expect that the cultivated functional organs can be implanted into living body together with the FSM of HA used as a scaffold. Here, we have to note that the FSM of HA should be crystallized because amorphous HA is promptly degraded in media for cell cultivation. In the previous study, we have a problem on the too long process time for the preparation of FSM of HA, which is approximately 26 hours for $6.5 \mu \mathrm{m}$ thick FSM of HA. The bottleneck is the crystallization process of HA occupying 20 hours, i.e., $\approx 77 \%$ of the total process time.

The fundamental preparation process of the FSM of HA is to deposit HA layer on solvent-soluble substrate, e.g., water-soluble $\mathrm{NaCl}$ crystal [2] [4] [9], acetonesoluble photoresists (polymer materials for micro-patterning) [3] [5] [6] [7] [8] and so on. The solvent-soluble substrates that we employed to date, i.e., $\mathrm{NaCl}$ and photoresists, have no heatproof properties while heating up to several hundred ${ }^{\circ} \mathrm{C}$ is needed to prepare crystallized HA layer. Therefore, as-deposited HA layer was amorphous on such substrates. A post-anneal for crystalizing has been performed after separation of FSM of HA by means of soaking the samples into appropriate solvent to dissolve the substrates. In a series of the preparation process, the longest one is the post-annealing of 20 hours while it took only 5 hours (for $6.5 \mu \mathrm{m}$ thick HA) and 1 hour for the deposition of HA and the dissolution of the solvent-soluble substrates, respectively. If we develop a novel process for direct preparation of crystallized FSM of HA, we can shrink the process time drastically. To realize the demand, we propose to deposit heatproof and water-soluble $\mathrm{Ba}$-compounds as a sacrificial layer between $\mathrm{HA}$ layer and $\mathrm{Al}_{2} \mathrm{O}_{3}$ (0001) single crystal. Because the $\mathrm{Ba}$-compounds and the $\mathrm{Al}_{2} \mathrm{O}_{3}(0001)$ single crystal are heatproof materials, crystallized HA layer can be directly deposited on Ba-compounds. In this short report, we report the preliminary results for the trial to use the sacrificial layer of heatproof and water-soluble Ba-compounds as the first step to reduce the preparation process time of FSM of HA.

\section{Experiment}

Ba-compounds and $\mathrm{HA}$ were deposited on $\mathrm{Al}_{2} \mathrm{O}_{3}$ (0001) single crystal substrates (K \& R Creation, Ikeda, Japan; $10 \times 10 \times 0.5 \mathrm{~mm}^{3}$, one-side polished) using pulsed laser deposition (PLD) with a KrF excimer laser (Coherent, Santa Clara, USA; COMPex 102). Here, the PLD is a kind of physical vapor deposition techniques. In the PLD, atomic vapor as a source of thin films are generated by means of "ablation phenomena" which is an explosive decomposition of solid surface (so-called "target”) irradiated with a high density ns laser pulse, typically $\mathrm{KrF}$ excimer laser. Generally, chemical composition of target is same with that of thin film to be deposited because the atomic vapor in the PLD has approximately similar chemical composition to the target. This means the PLD is appropriate for thin film deposition of materials with complicate chemical composition. The details of the experimental setup and parameters on the deposition condition are described in Figure 1 and Table 1. First, the Ba-compounds of sacrificial layer was deposited on the $\mathrm{Al}_{2} \mathrm{O}_{3}$ (0001) substrates followed by the deposition of $\mathrm{HA}$ 


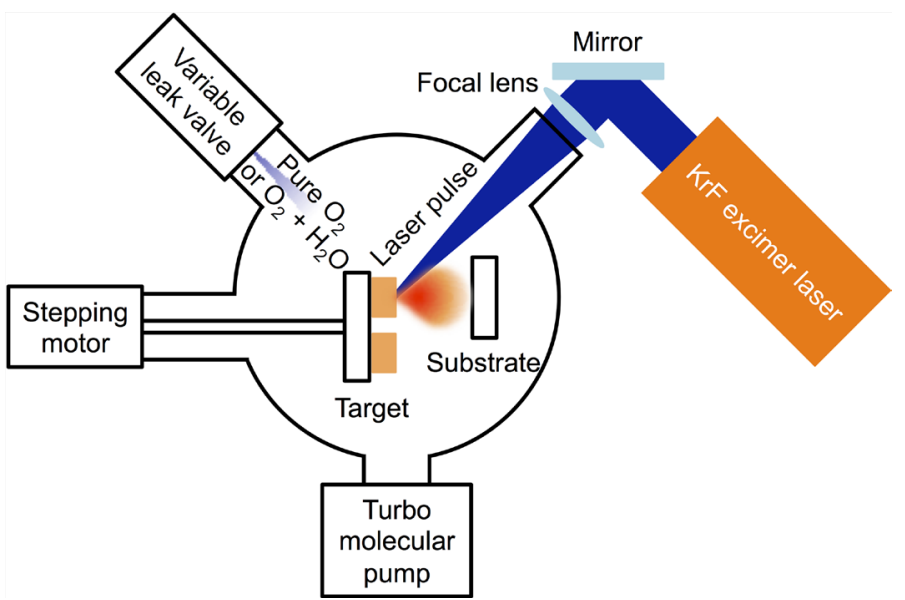

Figure 1. The schematic illustration of PLD setup used in this study.

Table 1. Growth parameters during the deposition of Ba-compounds and HA using PLD.

\begin{tabular}{|c|c|c|}
\hline & Ba-compounds & HA \\
\hline Substrate temperature $\left[{ }^{\circ} \mathrm{C}\right]$ & & \\
\hline Pulse repetition rate of ablation laser $[\mathrm{Hz}]$ & 2 & 5 \\
\hline Ambient gas & $\mathrm{O}_{2}$ & $\mathrm{O}_{2}+\mathrm{H}_{2} \mathrm{O}$ \\
\hline Partial pressure of ambient gas $[\mathrm{Pa}]$ & & \\
\hline Deposition time $[\mathrm{h}]$ & 1 & 5 \\
\hline Thickness $[\mu \mathrm{m}]$ & 1.5 & 6.5 \\
\hline Used target & Ba metal ${ }^{\mathrm{a}}$ & Cellyard $\AA^{\mathrm{b}}$ \\
\hline
\end{tabular}

${ }^{a}$ Rare Metallic, Tokyo, Japan; Disk-shape Ba metal with the purity of 99\%; ' $H O Y A$ Technosurgical, Tokyo, Japan; Plate-shape HA with the purity of $99 \%$ and the density of $99 \%$.

layer with the each thickness of described value in Table 1. After the deposition, the crystal structures of the sample were evaluated via X-ray diffraction (XRD) apparatus (Rigaku, Akishima, Japan; Ultima IV) [2]-[9] using conventional $2 \theta / \theta$ measurements. The thickness of deposited thin films was measured using a stylus surface profiler (Bruker USA (Optical Profilers and Stylus Profilers), Tucson, USA; Dektak 150). Then, the sample was soaked into distilled water at room temperature for 1.5 hours to dissolve the Ba-compounds of the sacrificial layer.

\section{Results and Discussion}

First, we examined the deposition of Ba-compound layer on the $\mathrm{Al}_{2} \mathrm{O}_{3}$ (0001) substrate. The XRD pattern of $1.5 \mu \mathrm{m}$ thick Ba-compound layer is shown in Figure 2. It is concluded that the deposited Ba-compound was single phase $\mathrm{Ba}(\mathrm{OH})_{2} \cdot \mathrm{H}_{2} \mathrm{O}$. However, we consider that the deposited Ba-compound was not $\mathrm{Ba}(\mathrm{OH})_{2} \cdot \mathrm{H}_{2} \mathrm{O}$ just after the deposition because its melting point is $78^{\circ} \mathrm{C}$ at the standard pressure. $\mathrm{Ba}(\mathrm{OH})_{2}$, the parent material of $\mathrm{Ba}(\mathrm{OH})_{2} \cdot \mathrm{H}_{2} \mathrm{O}$, has also low melting point of $408^{\circ} \mathrm{C}$ compared to the substrate temperature during the deposition. Here, we ablated Ba metal target in a pure oxygen atmosphere as described in Table 1. Judging from the experimental condition in this study, we 
speculated that the initial deposited layer was $\mathrm{BaO}$, whose melting point is $1923^{\circ} \mathrm{C}$ at the standard pressure, i.e., much higher than the substrate temperature. While the $\mathrm{Ba}$-compound remained $\mathrm{BaO}$ in the growth chamber, it will change into $\mathrm{Ba}(\mathrm{OH})_{2}$ compounds via chemical reaction with the water vapor in the air owing to its ease of chemical reaction to water, once it was taken out from the growth chamber.

On the next step, we tried to prepare bilayer of HA and Ba-compound. Figure 3 shows the XRD pattern of the bilayer sample. One can find HA diffraction peaks in addition to the diffraction peaks of $\mathrm{Ba}(\mathrm{OH})_{2}$ compounds. This means that both of two layers are successfully crystallized during the deposition. The diffraction peaks of $\mathrm{Ba}(\mathrm{OH})_{2}$ compounds are different from that in Figure 2. However, the appeared diffraction peaks for all samples were assigned completely as that of the $\mathrm{Ba}(\mathrm{OH})_{2}$ compounds. It will come from the large difference of effective surface areas for the chemical reaction, i.e., the surface is only four planes at the sidewalls with the heights of layer thickness in the case of the bilayer while whole of top most plane can be a field for the chemical reaction in the case of the Ba-compound single layer. The difference must be investigated in detail as a next subject.

In Figure 4, a photograph is shown for FSM of HA which was retrieved from the bilayer sample by means of dissolution of the $\mathrm{Ba}(\mathrm{OH})_{2}$ compound layer. The soaking time was 1.5 hours. The cross-like shape came from no depositions at the four corners of substrate because of holding the substrate using small plates with the size of approximately $3 \times 3 \mathrm{~mm}^{2}$ during the PLD process. The result

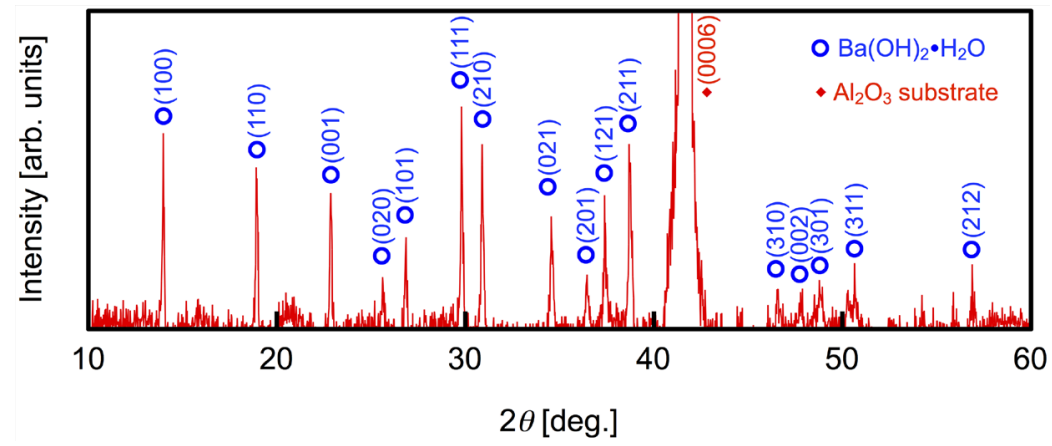

Figure 2. XRD pattern of Ba-compound layer deposited on $\mathrm{Al}_{2} \mathrm{O}_{3}(0001)$.

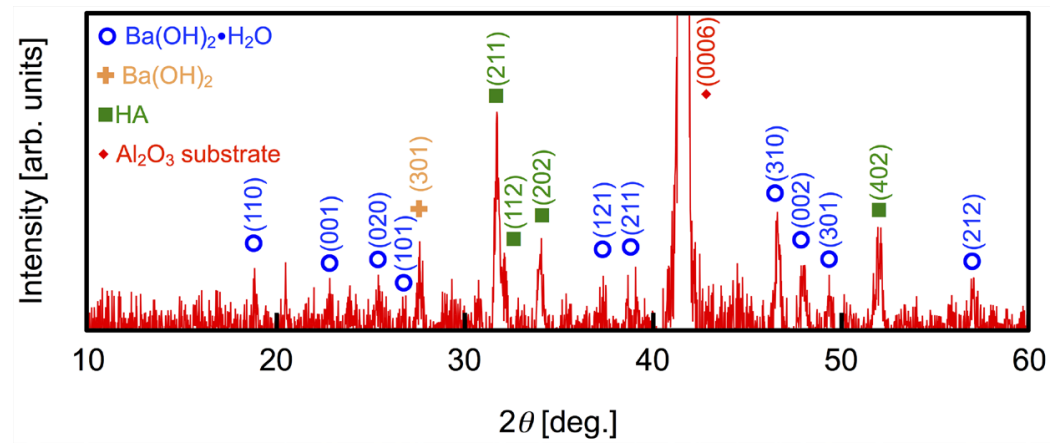

Figure 3. XRD pattern of bilayer of $\mathrm{HA}$ and $\mathrm{Ba}$-compound deposited on $\mathrm{Al}_{2} \mathrm{O}_{3}(0001)$. 


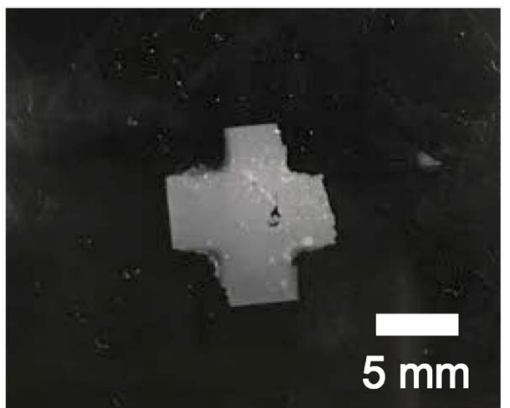

Figure 4. Photograph of retrieved crystallized FSM of HA.

indicates that the direct preparation of crystallized FSM of HA was realized owing to an appropriate sacrificial layer, i.e., water-soluble Ba-compounds examined in this study. The successful process proposed in the study is expected to be a critical technique for reducing the preparation time of crystallized FSM of HA. On the previous process requiring post-annealing, it took 20 hours for just annealing to crystallize a FSM of HA as above mentioned. On the novel process proposed in this study, this 20 hours process is substituted the deposition time of Ba-compounds layer as an appropriate sacrificial layer, only 1 hour, meaning 19 hours saving. The total process time is shrunk from 26 hours to 7.5 hours, i.e., by $\approx 71 \%$ in this novel process.

The novel process proposed in this study is not completed because we have not verified the crystallization of the retrieved FSM of HA via XRD, while it must be crystallized because HA diffraction peaks were found in the XRD pattern as shown in Figure 3 before the retrieval. The crystallized FSM of HA prepared in this study did not show enough bendable property to handle at will. Thus it was broken into small pieces before the measurement of XRD. In the next study, we will examine to improve the bendable property of the crystallized FSM of HA prepared in this novel process using Ba-compounds sacrificial layer.

In this study, we have tried only a proportion of Ba-compound and HA thickness, $1.5 \mu \mathrm{m}$ and $6.5 \mu \mathrm{m}$, respectively. Depending on the thickness proportion of these layers, the roughness of the FSM of HA must be varied. Because the roughness of the FSM of HA will affect its bendable property thorough the nonuniformity of the thickness, to change the thickness proportion of two layers has a possibility to improve the bendable property, i.e., handling ease. So, we will try different thickness proportion of these two layers as a next step to measure the $\mathrm{XRD}$ and observe the surface using scanning electron microscope while these evaluations cannot be performed due to the poor mechanical property in the present.

\section{Conclusion}

We have proposed a direct process to prepare crystallized FSM of HA, whose purpose is to reduce the process time. Because the bottleneck was the postannealing to crystallize the amorphous FSM of HA of 20 hours, we have examined the deposition of a heatproof and water-soluble sacrificial layer, i.e., 
Ba-compounds before the deposition of HA layer to crystallize HA layer directly without post-annealing of the bottleneck. It was achieved successfully to retrieve the crystallized HA layer deposited on the Ba-compounds sacrificial layer by means of the soaking into distilled water. The successful retrieving the crystallized FSM of HA is the great first step into the complete development of the novel process to reduce the process time.

\section{Acknowledgements}

This work was supported in part by the Strategic Research Foundation Grantaided Project for Private Universities from the Ministry of Education, Culture, Sports, Science, and Technology, Japan, 2013-2017 (No. S1311045).

\section{References}

[1] Leukers, B., Gulkan, H., Irsen, S.H., Milz, S., Tille, C., Schieker, M. and Seitz, H. (2005) Hydroxyapatite Scaffolds for Bone Tissue Engineering Made by 3D Printing. Journal of Materials Science: Materials in Medicine, 16, 1121-1124. http://dx.doi.org/10.1007/s10856-005-4716-5

[2] Nishikawa, H., Hatanaka, R., Kusunoki, M., Hayami, T. and Hontsu, S. (2008) Preparation of Freestanding Hydroxyapatite Membranes with Excellent Biocompatibility and Flexibility. Applied Physics Express, 1, 088001. http://dx.doi.org/10.1143/APEX.1.088001

[3] Kusunoki, M., Kawakami, Y., Matsuda, T., Nishikawa, H., Hayami, T. and Hontsu, S. (2010) Fabrication of a Large Hydroxyapatite Sheet. Applied Physics Express, 3, 107003. http://dx.doi.org/10.1143/APEX.3.107003

[4] Hontsu, S., Yoshikawa, K., Kato, N., Kawakami, Y., Hayami, T., Nishikawa, H., Kusunoki, M. and Yamamoto, K. (2011) Restoration and Conservation of Dental Enamel using a Flexible Apatite Sheet. Journal of the Australian Ceramic Society, 47, 11-13.

[5] Hontsu, S., Kato, N., Yamamoto, E., Nishikawa, H., Kusunoki, M., Hayami, T. and Yoshikawa, K. (2011) Regeneration of Tooth Enamel by Flexible Hydroxyapatite Sheet. Key Engineering Materials, 493-494, 615-619. http://dx.doi.org/10.4028/www.scientific.net/KEM.493-494.615

[6] Yamamoto, E., Kato, N., Nishikawa, H., Kusunoki, M., Hayami, T., Yoshikawa, K. and Hontsu, S. (2012) Adhesive Strength between Flexible Hydroxyapatite Sheet and Tooth Enamel. Key Engineering Materials, 529-530, 522-525. http://dx.doi.org/10.4028/www.scientific.net/KEM.529-530.522

[7] Kusunoki, M., Matsuda, T., Fujita, N., Sakoishi, Y., Iguchi, R., Hontsu, S., Nishikawa, H. and Hayami, T. (2013) Control of Crystallinity of Hydroxyapatite Sheet. Key Engineering Materials, 583, 47-50. http://dx.doi.org/10.4028/www.scientific.net/KEM.583.47

[8] Kato, N., Isai, A., Yamamoto, E., Nishikawa, H., Kusunoki, M., Yoshikawa, K., Yasuo, K., Yamamoto, K. and Hontsu, S. (2015) Evaluation of Dentin Tubule Sealing Rate Improved by Attaching Ultrathin Amorphous Calcium Phosphate Sheet. Key Engineering Materials, 631, 258-261. http://dx.doi.org/10.4028/www.scientific.net/KEM.631.258

[9] Hashimoto, Y. Nishikawa, H., Kusunoki, M., Li, P.Q. and Hontsu, S. (2015) A Novel Membrane-type Apatite Scaffold Engineered by Pulsed Laser Ablation. Dental Materials Journal, 34, 345-350. http://dx.doi.org/10.4012/dmj.2014-299 
Submit or recommend next manuscript to SCIRP and we will provide best service for you:

Accepting pre-submission inquiries through Email, Facebook, LinkedIn, Twitter, etc. A wide selection of journals (inclusive of 9 subjects, more than 200 journals)

Providing 24-hour high-quality service

User-friendly online submission system

Fair and swift peer-review system

Efficient typesetting and proofreading procedure

Display of the result of downloads and visits, as well as the number of cited articles Maximum dissemination of your research work

Submit your manuscript at: http://papersubmission.scirp.org/

Or contact jcpt@scirp.org 